\title{
Shaping the Future of Academic Health Centers: The Potential Contributions of Departments of Family Medicine
}

Warren P. Newton, MD, MPH, Guest Editor ${ }^{1}$

C. Annette DuBard, $M D^{2}$

${ }^{'}$ William B. Aycock Professor and Chair, Department of Family Medicine ${ }_{i}$ Adjunct Professor, Department of Epidemiology, University of North Carolina at Chapel Hill School of Medicine, Chapel Hill, NC

${ }^{2}$ Department of Famiy Medicine, University of North Carollina at Chapel Hill School of Medicine, Chapel Hill, NC

Conflicts of interest: none reported

\section{CORRESPONDING AUTHOR}

Warren P. Newton, MD, MPH Department of Family Medicine University of North Carolina at Chapel Hill School of Medicine CB\#7595 William B. Aycock Bldg Chapel Hill, NC 27599-7595

Warren_Newton@med.unc.edu

\begin{abstract}
Academic health centers (AHCs) must change dramatically to meet the changing needs of patients and society, but how to do this remains unclear. The purpose of this supplement is to describe ways in which departments of family medicine can play leadership roles in helping AHCs evolve. This overview provides background for case studies and commentaries about the contribution of departments of family medicine in 5 areas: (1) ambulatory and primary care, (2) indigent care, (3) education in community and international settings, (4) workforce policy and practice, and (5) translational research.

The common theme is a revitalization of the relationship between AHCs and the communities they serve across all missions. Family medicine leadership can provide dramatic organizational improvement in primary and ambulatory care networks and foster opportunities for leadership by AHCs in improving the health of the population. Departments of family medicine can also play a leading role in developing new partnerships with community-based organizations, managing the care of the indigent, and developing new curricula in community and international settings. Finally, family medicine departments and their faculty have a central role in helping AHCs respond to workforce needs and in developing translational research that emphasizes the health of the population and effectiveness of care.

AHCs are a public good that must now evolve substantially to meet the needs of patients and society. By pushing for substantial change, by helping to reinvigorate the relationship between AHCs and the communities they serve, and by emphasizing fundamental innovation in clinical care, teaching, and research, family medicine can help lead the renewal of the AHC.
\end{abstract}

Ann Fam Med 2006;4(Suppl 1):S2-S11. DOI: 10.1370/afm.587.

\section{INTRODUCTION}

decade ago, many academic medical leaders prophesied the melt-
down of the academic health center (AHC). After 3 decades of
expansion as the result of federal support for clinical care and research, the argument went, the slowdown of National Institutes of Health (NIH) funding combined with the Balanced Budget Act and widespread restructuring of the medical marketplace would lead to grave financial difficulties in AHCs. ${ }^{1-5}$ Many predicted that a majority of the nation's academic medical centers would face major financial deficits by the year 2000, with grave consequences for the education and research missions that depended on cross-subsidies. Rumors of an early demise proved exaggerated, however, as NIH funding surged and academic centers adopted a variety of strategies to respond to changes in the health care marketplace. 
These strategies included vigorous cost-cutting efforts, centralization of management, expansion of outpatient services, growth of academic-industrial relationships, and merging to form integrated health care systems. ${ }^{6}$

Despite these recent successes, the Institute of Medicine (IOM) ${ }^{6}$ and others ${ }^{7-9}$ believe that AHCs must evolve dramatically to ensure the survival of core missions. AHCs must adapt to a variety of different and powerful trends: (1) patient needs are changing, associated with the aging of the population, the dramatic rise of chronic disease, and a large influx of patients from different cultures, (2) financing streams supporting education and research are continually under threat, and (3) marketplace dynamics are forcing AHCs to compete more aggressively, while the rising numbers of uninsured and underinsured individuals and the need for major investment in information management strain existing resources. At the same time, medical innovation is occurring at an unbelievable pace, and our evolving capacity to analyze the effectiveness of care reveals dramatic geographic variation in expense unrelated to outcomes. There are large disparities in outcomes related to race/ethnicity and socioeconomic status, high rates of serious medical errors, and population health outcomes substantially worse than those of other western countries. All of this takes place in a context of high social expectations for medicine, increasing emphasis on care that is organized around patients rather than clinicians, ${ }_{1}^{10}$ and rising demand for accountability of the profession.

Without substantial change, then, AHCs risk irrelevance to society's most pressing needs. As the authors of the IOM report argue, the need for change in AHCs is urgent and spans all traditional missions. ${ }^{6}$ In clinical care, for example, we must turn our focus toward improving care for diabetes in outpatient offices and preventing the need for inpatient care. In education, we should refocus our attention outward, revitalize our curriculum by extending it into the communities we serve, and, in doing so, underscore cultural competence. In research, we must broaden our focus from the bench to the bedside and, thence, to the community, with more emphasis on effectiveness of care and the health of the population. Importantly, achieving these goals will also require substantial organizational changes within the AHCs, breaking down "silos" of individual disciplines, fostering and rewarding collaborative efforts, and developing faster decision-making cycles.

It is in this context of a major transformation of AHCs that we consider the development of family medicine and its potential contributions to AHCs. In the 40 years since its founding, family medicine has been remarkably successful. Family physicians now comprise the largest single group of physicians, exceeded only by the combined subspecialties of internal medicine. ${ }^{10}$ Family physicians have more patient visits annually than general surgeons, pediatricians, and obstetrician-gynecologists combined, ${ }_{1}^{10}$ and large majorities of patients with each of the most common chronic diseases identify a family physician as their usual source of care. ${ }^{10}$ Despite such prominence in the care of the population, however, the status of departments of family medicine in AHCs is uneven. In a recent survey of deans, family physician faculty were seen as comparable to other primary care faculty in clinical care and teaching, but less adept in research. ${ }^{11}$ Eleven medical schools, clustered in private institutions in the Northeast, have yet to create a department of family medicine.

The premise of this supplement to Annals of Family Medicine is that departments of family medicine have a substantial role to play in helping AHCs remain relevant and lead the necessary transformation of American medicine. This overview will provide a brief historical and policy context for opportunities for transformation of the AHC in 5 focus areas: organization and financing of ambulatory care in primary care settings, provision of care to the indigent, education in community and international settings, workforce development, and translation of research from the bench to the community. We define AHCs as health centers that include a medical school and a teaching hospital, usually with associated health professional schools, and recognize that these issues are relevant to an increasing number of large regional medical centers with substantial educational and research missions.

Case studies presented in this supplement were chosen from reports of "best practices" presented at the annual meeting of the Association of Departments of Family Medicine (ADFM) or were suggested by leaders of the academic organizations of family medicine. Final choices were made by the Council of Academic Societies representatives and leadership of the ADFM, the Society of Teachers of Family Medicine (STFM), the North American Primary Care Research Group (NAPCRG), the Association of Family Medicine Residency Directors (AFMRD), the American Board of Family Medicine (ABFM), and the American Academy of Family Physicians (AAFP). After initial peer review, papers were presented at the fall 2005 Association of American Medical Colleges (AAMC) annual meeting; oral questions and commentary were incorporated into the peer-review process. Formal commentaries were requested of leaders in academic medicine with known expertise in the specific areas, as well as the leadership of the Council of Academic Societies, the Council of Deans, and the AAMC; these commentaries also were peer-reviewed. 


\section{Ambulatory and Primary Care}

The last 20 years have seen a dramatic change in the role of the hospital in health care. Between 1980 and 1999, the number of days of hospitalization per 1,000 population annually dropped by one half: from 819 to 317 among younger adults, and from 4,098 to 2,257 among the elderly. ${ }^{12}$ This drop was the consequence of several interrelated trends-improvements in care, changes in medical practices, and the drive to reduce the cost of care. Paralleling and strengthening these trends have been dramatic shifts in methods of reimbursement, with the imposition of Diagnosis-Related Groups in the mid-1980s and the growth of capitation in the 1990s. The net result of all of these trends has been a massive transfer of care from the hospital to the office or outpatient setting.

The implications of this shift are large. Physicians of all specialties have revised their approaches to provide in the outpatient setting what was formerly done on an inpatient basis, hospital systems have progressively geared themselves to shorter stays, and the rise of the hospitalist movement has focused further attention on the cost-effectiveness of inpatient care. Of course, teaching hospitals have operated outpatient dispensaries for almost 2 centuries, but these pressures have forced hospitals to provide as much care as possible in an outpatient venue. By 2003, about $60 \%$ of the average hospital's operating margin thus depended on outpatient revenues. ${ }^{13}$ The dramatic growth of ambulatory operations has required new organizational structures in AHCs, including designated ambulatory leadership, new financing models, and different relationships between hospitals and physicians.

During this time, many AHCs acquired or developed primary care networks to capture "covered lives" and ensure referrals into the AHC system. ${ }^{2,3}$ This proved to be a high-risk strategy, and the benefits of vertical integration have often been elusive. Many academic institutions had no tradition of employing primary care physicians and have faced new structural and cultural challenges in managing primary care networks. ${ }^{1-3}$ As capitation receded in many markets, primary care networks often began to lose substantial amounts of money. ${ }^{14-16}$ The case study offered by Magill and colleagues ${ }^{17}$ describing events at the University of Utah demonstrates how departments of family medicine may be uniquely well suited for leadership in this situation. Family medicine faculty often have substantial clinical and managerial experience in outpatient care, and bring a focus and expertise of critical value as AHCs struggle to make primary care networks fiscally viable. The accompanying commentary by Krugman ${ }^{18}$ contrasts the University of Utah experience with the University of Colorado experience and underscores the important role of governance and related academic missions.

Fiscal viability, however, is not the whole picture. The relatively new prominence of ambulatory and primary care within AHCs offers substantial opportunity to address questions of quality and effectiveness in primary care with greater academic vigor. The largest platform of health care delivery in the United States is the small to medium-sized physician practice-not the AHC. Family physicians provide a much larger number of face-to-face patient encounters in these practices than do physicians of any other specialty ${ }^{10}$ and are far more likely than subspecialists or other generalists to be the usual source of care for patients with chronic diseases, including coronary vascular disease, asthma, heart failure, chronic obstructive pulmonary disease, depression, diabetes, and hypertension. ${ }^{10}$ Our current ambulatory care systems, moreover, are largely based on a model of acute care that came to maturity in the 1950s, when trauma and minor infectious disease were major reasons for seeing patients, and before the dramatic growth of chronic disease. ${ }^{19}$ Evidence of a quality chasm between achievable care and actual care in the outpatient setting, as well as health disparities and unequal access issues, have mounted in recent years, ${ }^{20-22}$ creating an imperative for substantial change in ambulatory care. Primary care practices of the future will require dramatic redesign, ${ }^{23-26}$ with multidisciplinary approaches to patient-centered care, infrastructure reform with advanced scheduling and billing systems, and clinical systems that facilitate measurement of quality and active management of chronic disease.

Academic centers have an opportunity to provide leadership in primary care. Although AHCs have traditionally led development of innovation in new technologies in subspecialty and hospital care, they have failed to emerge as leaders in the testing and diffusion of innovative health services delivery at the level of primary or population care. To the contrary, as asserted by a recent report funded by the Robert Wood Johnson Foundation, quality improvement initiatives appear to be "orders of magnitude more difficult" to implement in academic centers than in community settings ${ }^{27}$ and will likely remain so until evidence-based system redesign becomes a priority. Visits in hospital outpatient departments are characterized by greater costs and service intensity, and poorer continuity of primary care than visits in community health centers and physicians' offices. ${ }^{28}$ Ownership of primary care practices creates new opportunities for AHCs to lead change in a setting in which the potential for impact on the health of the population is greatest. 


\section{Indigent Care}

Seventy-five percent of the nation's 126 AHCs are seated within communities of underserved populations, ${ }^{29}$ and care of the medically indigent and vulnerable populations is a key component of the mission of most AHCs. Historically, the provision of indigent care has always been linked to medical student and house staff education, both in the inpatient setting and in the dispensary or clinic setting. With the rise in numbers of uninsured and underinsured in recent years, however, AHCs are seeing substantial increases in the cost of indigent care. Hospitals have reported dramatic increases in charity and bad debt over the last 20 years, ${ }^{30}$ reflected in both the absolute costs of care and the relative impact on net revenues. Academic centers care for a large minority of all indigent patients, but indigent care represents a disproportionately large segment of their inpatient, and increasingly outpatient, care. Teaching hospitals represent $6 \%$ of the nation's hospitals but provided $40 \%$ of the nation's hospital charity care in $2000 .^{31}$

The financial impact of indigent care on AHCs has been compounded by the challenges of the larger health care economic environment. Modern medicine and especially academic medicine is a capital-intensive industry, requiring a large operating margin to continue to invest in physical facilities and technology. Prospective payment, utilization constraints, decreases in clinician reimbursement by Medicare and other insurers, and slowdowns in other sources of federal support have limited the ability of AHCs to subsidize their missions of research, education, and indigent care. The increasing cost of indigent care thus threatens the core missions of the AHC.

How have AHCs responded? Not surprisingly, many have responded with attempts to limit access to care in a variety of ways, such as increasing wait times for appointments or demanding advance payment for services. Some, however, have responded more proactively, identifying ways to provide more effective and efficient care rather than less care. In the absence of a usual source of care, uninsured patients may overly rely in emergency departments as a point of care, thus greatly inflating the costs of care. With the recognition that the uninsured represent one of the last "unmanaged" populations remaining in a highly managed medical marketplace, health systems have begun to look for cost saving through improved coordination of services for this population.

Efforts to manage the care of the uninsured range greatly in degree. At a minimal level are attempts to reduce demand through health education or outreach clinics. At the other end are more ambitious efforts to transform the regional health care landscape, identify- ing and developing partnerships with private primary care clinicians, community health centers, and state and local agencies to develop organized networks of care. ${ }^{32-34}$ Community partners may be better equipped to provide access to culturally competent care, and a robust primary care system is the best antidote to avoidable hospitalizations and emergency department visits. Case management programs for high users can target support for patients at highest risk, and disease management programs and coordinated mental health services may also prove cost-effective. Communityacademic partnerships have the potential to improve the health of the community, further the service missions of schools, and often provide educational opportunities for both learners and community clinicians. ${ }^{35-39}$

The case study by Kaufman and colleagues ${ }^{40}$ at the University of New Mexico conveys the enormous potential of effective academic-community partnerships for improving the care of the uninsured while cutting avoidable costs. Like many AHCs, the University of New Mexico has been the major source of care for a large uninsured population spread over a large geographic area. In a series of initiatives spanning a decade, however, the institution has put in place the elements of a comprehensive system of care for the uninsured. These elements include a primary care home, affordable copayments for visits and medications, and integration of public health, medical, behavioral, and social services into common sites at the community level. The Department of Family Medicine provided key intellectual and organizational leadership in bringing together various units of the academic center and building bridges with community partners. The commentary by Roth ${ }^{41}$ puts the University of New Mexico's strategy in national context, contrasts investment in tertiary and quaternary care and in prevention and primary care, and underscores the political context of care for the uninsured.

\section{Education}

Powerful forces of change in health care delivery and renewed emphasis on population-based thinking in health care will require equally substantial reform in the educational mission of AHCs. We must consider how the clinical setting of education should prepare graduates to practice in modern health care settings. As described originally by White and others ${ }^{42}$ and replicated with current data by Green and others, ${ }^{43}$ the vast majority of care takes place in community-based outpatient practices, substantially distinct from AHCs. Nearly 1 billion ambulatory visits are made annually in the United States, compared with 32 million hospitalizations, ${ }^{12}$ but medical school curricula often place a major emphasis on the delivery of tertiary services 
in the inpatient setting, and reform without change is common. ${ }^{44,45}$ With trends toward shorter hospital stays and much diagnostic evaluation being done before hospital admission, learners who remain in hospitals may lose some of the intellectual opportunity to approach undifferentiated patient complaints, as well as the opportunity to establish relationships with patients that offer insight into the myriad individual determinants of health and well-being. ${ }^{46-48}$ Reflecting this shift, the recent AAMC policy statement underscored the need for considerable change in clinical curricula to reflect contemporary clinical practice as well as to support teachers and teaching. ${ }^{49}$

It is clear that the clinical settings of the future will look very different from those of the past. The aging of the population, the rise in chronic illness, and technologic advances all contribute to an increasing shift in medical care to an office and community focus. Twenty-first century challenges require training beyond the traditional biomedical focus, to incorporate social, cultural, behavioral, and environmental influences on population health and prevention. These challenges also require better background on resource allocation and should emphasize chronic disease in addition to acute disease management. ${ }^{50-52}$ Physicians must be adept at information management and critical appraisal of the literature, and prepared to work effectively within interdisciplinary teams and with community partners to deliver patient-centered care. AHCs are called on, then, to cultivate physicians who are not just healers, researchers, and educators, but also leaders, managers, and public health partners. ${ }^{53}$

Financing mechanisms for clinical education that are oriented toward hospital inpatient care (via direct and indirect payments by Medicare for graduate medical education) are thus increasingly out of synchrony with the public good. ${ }^{54,55}$ Unfortunately, capacity for sustaining educational activities in AHCs is simultaneously threatened by narrower operating margins in the current health care marketplace, associated with trends toward reduced federal subsidies for physician education. ${ }^{56}$ In addition, shifting medical education to ambulatory settings presents considerable challenges beyond the disincentives inherent in current financing streams. Although more than one half of surveyed young physicians believe that they had too little training in physician offices, organized care settings, or long-term care facilities, ${ }^{57}$ students generally rate the quality of instruction in ambulatory settings lower than that in inpatient settings. ${ }^{7}$ The need for accreditation and oversight of educational programs in ambulatory settings, as well the need for faculty development and organization, present further obstacles to the development of strong ambulatory education. The evidence base for determinants of quality and effectiveness in clinical education remains weak, leaving little to guide AHCs as they implement changes that will better prepare students for their future in clinical practice. ${ }^{6}$

Training physicians to be aware of - and act ontheir social responsibility should also be an important part of the curriculum. It is notable that the social status of physicians, as reflected in opinion polls, has declined substantially during the last 5 years. ${ }^{58}$ To be sure, medicine's successes are chronicled extensively, and physicians continue to have high prestige, but over the last 5 years, there has been a marked drop in the prestige attributed to this profession. This relative decline in status is greater than the drop of status in the clergy associated with widespread publicity about sexual abuse scandals. ${ }^{58}$ The last 10 years has also seen a relative decline in applications to medical schools, ${ }^{59}$ despite the increase in number of women coming into medicine. These shifts may reflect that, to some extent, the profession of medicine is under siege by a combination of adverse trends: the steady negative publicity of liability suits; ethical lapses at major professional societies, major journals, and the $\mathrm{NIH}_{i}$ and the juxtaposition of astronomical salaries made by some physicians alongside escalating health care costs increasingly borne out of pocket by consumers. In this context, an emphasis on service for medical students in underserved communities, abroad, or both strikes a particularly positive chord for students, and development of curricula addressing "meaning in medicine" have also proved extraordinarily attractive. ${ }^{60,61}$

Community-based and international education is an area of traditional emphasis and strength for family medicine. In many institutions, and facilitated by Title VII funding, departments of family medicine have taken a leadership role in curricular innovation. The case study presented by Smith and Weaver ${ }^{62}$ provides one example of such leadership - an international elective that successfully brings vitality to the medical curriculum, promotes understanding of the social and environmental determinants of health, and nurtures the idealism and compassion of students. The commentary by Eckhert ${ }^{63}$ gives a national perspective on the increasingly recognized need to prepare students to work in the global community and discusses the measures by which we might determine success.

\section{Workforce Planning}

Training physicians was the original and unquestioned purpose of medical schools. In the 1960s and 1970s, the United States doubled the number of medical graduates, recognizing that it was important to provide physicians to meet the needs of the population. It was this rationale that justified the development of the new 
discipline of family medicine as well as parallel initiatives to build more hospitals and develop new disciplines of clinicians, such as physician's assistants and nurse-practitioners. The landmark 1981 report on physician workforce from the Graduate Medical Education National Advisory Committee (GMENAC) ${ }^{16}$ codified this "planning approach" to physician workforce planning based on estimates of population growth. The authors predicted that by the year 2000, there would be an excess supply of specialist physicians. The Bureau of Health Professions, the Council on Graduate Medical Education (COGME), ${ }^{64}$ and others long espoused such needs-based methods, endorsing policies that aimed to restrict specialist training and increase the ratio of generalists to specialists.

In recent years, however, a different approach to estimating workforce need has gained popularity. Emphasizing the influence of economic growth on demand for physicians, Cooper and others ${ }^{65,66}$ have argued that we are now facing a shortage of specialists and perhaps an overabundance of primary care physicians. Assuming marked growth in the economy and allowing for marketplace allocation of physicians, Cooper's supply-demand model argues that economic growth will increase demand for specialist care. His work has influenced COGME to recommend increases in physician training, without any special attention to primary care. ${ }^{64}$ Similarly, the AAMC has recently called for removal of Medicare restrictions on funded positions to allow AHCs to respond to physician workforce market dynamics.

The differences in workforce projection between planning-based and demand-based models are substantial. Workforce models are often imbued with professional self-interest, and many methodologic issues remain controversial. Neither of these approaches considers the impact of new models of care, although we know that the enormous growth in the numbers of allied health professionals and substantial changes in care delivery are transforming practice. In a recent comparison of 3 methods for estimating family physician workforce needs - a planning model, a supply and demand model, and an estimate of need based on new models of care-analysts noted that the estimated number of family physicians necessary varies by more than 50,000 physicians! ${ }^{67}$ Importantly, the characteristically uneven distribution of physicians in America means that an increase in per-capita physician supply alone is not sufficient to resolve problems of access to care in many populations of patients.

Empirical evidence increasingly shows, however, that the proportion of primary care clinicians and their integration into the health care system are strongly correlated with both quality and cost-effectiveness of health care of the population. ${ }^{68-71}$ In contrast, greater specialist supply is not associated with better population health and is more likely to inflate health care costs. ${ }^{72-74}$ Value-neutral approaches such as that espoused in market demand-based models fail to address this situation. If quality and cost-effectiveness of care for the population are important, the balance of generalists to subspecialists is a key leverage point for governmental policy.

How should AHCs respond? For the public, training physicians remains a major mission of the $\mathrm{AHC}$. That mission requires that $\mathrm{AHC}$ s take a position on the workforce debate. The need for taking a stance has become increasingly urgent as interest in family medicine and primary care has dropped precipitously since the late 1990s, with worrisome implications for safety net clinicians. ${ }^{75}$ Even more pronounced has been the stunning drop in interest in general internal medicine among internal medicine residents, ${ }^{76}$ and strong shifts of physician's assistants, nurse-practitioners, and osteopathic physicians toward subspecialization. ${ }^{67}$ The case study presented in this supplement by Berg and Norris ${ }^{77}$ describes how the University of Washington, a wellregarded institution with both substantial NIH-funded research and an explicit mission to support primary care, decided to use workforce data to drive their educational policy, including admissions and curriculum design.

Social accountability of AHCs remains an important issue. Over the last decade, the World Health Organization has promoted an explicit call for the integration of social accountability into the education, research, and service activities of academic centers. Workforce development is a key element of that social accountability. ${ }^{78}$ In practice, this means "a systematic approach to addressing priority health needs, including issues of access to services, determining and educating the appropriate number and mix of physicians, and facilitating the geographic distribution necessary to meet the needs of the community." ${ }^{119}$ The commentary by Rourke ${ }^{80}$ provides a perspective on the role of AHCs from Canada, a nation whose medical schools have espoused the principle of social accountability and grappled with putting it into practice ${ }^{81} \mathrm{He}$ comments on the University of Washington approach and addresses both the specifics of workforce planning and the practical aspects of integrating responsibility for the health of a province and the management of a medical school.

\section{Research}

How can AHCs best contribute to improving the health of the population through research? For 2 generations, medical science has emphasized the discovery of basic mechanisms of disease and, at a clinical level, the development of increasingly sophisticated 
methods of diagnosis and treatment for individual patients. Over that time span, the NIH, along with other federal, philanthropic, and commercial funders of research, has reshaped the $\mathrm{AHC}$, adding research as a major mission of many schools and making possible a dramatic increase in the number of faculty and specialty training programs. This advance has been especially impressive over the last decade, as another explosion of work is leading to the development of genetically targeted testing and treatment strategies. The potential benefit of these advances for individual patients is tremendous.

Increasingly, however, as reflected in the IOM report ${ }^{6}$ leaders recognize that capacity for continued basic science discovery by itself is not sufficient. The full benefit of these discoveries is unlikely to be realized without greater focus on clinical, health services, and prevention research. ${ }^{6}$ The formal distinction is between efficacy - what ought to work in ideal circumstances - and effectiveness - what actually happens with usual patients in typical situations. More than 30 years ago, the classic study of Brook and colleagues $^{82}$ of the effectiveness of nonurgent care in the emergency department documented that, even in our most prestigious institutions, what actually happens to patients differs greatly from what we think should happen-and outcomes are much worse than we want to admit. With important exceptions, our academic culture has not prioritized the exploration of effectiveness, promoting technical triumph for individuals over benefits in practice for populations.

The "quality chasm" described by the $\mathrm{IOM}^{83}$ is thus not new, just newly listened to. Three basic streams of evidence document widespread lack of effectiveness in American medicine. The first relates to quality of care, with mounting reports documenting a quality gap in both inpatient and outpatient settings. ${ }^{20,21,83}$ Care patterns vary considerably between geographic regions, without strong relation to quality or outcomes; almost one half of adults in a national sample do not receive recommended care for prevention, acute episodes, or chronic conditions. ${ }^{20}$ Similarly, more than one half of patients with diabetes, ${ }^{84}$ hypertension, ${ }^{85}$ high cholesterol levels, ${ }^{86}$ congestive heart failure, ${ }^{87}$ chronic atrial fibrillation, ${ }^{88}$ asthma, ${ }^{89}$ depression, ${ }^{90}$ and tobacco addiction $^{91}$ do not receive proven treatment. ${ }^{21}$ As the IOM summarized, "there is a large gap between what we know and what we do." ${ }^{183}$

A second issue is equity. Despite a rhetoric of equity in American health care, disparities in health care access, quality, and outcomes related to race/ethnicity and socioeconomic status are pervasive and have been well documented across many clinical conditions and many care settings. ${ }^{92}$ Health disparities represent an important challenge to deeply held American values of equality. They demand correction.

Finally, the effectiveness of US health care is called into question by the health status of the population as a whole. Despite enormous investments in health care, the United States lags well behind other first world countries - and, indeed, increasing numbers of formerly third world countries - in both population health indicators and patient satisfaction. ${ }^{68,71}$

These are huge issues for American society as well as American medicine, and $\mathrm{AHCs}$, by nature and by design, are not yet well suited to addressing them. ${ }^{93}$ These issues are, however, the agenda for the future of care, ${ }^{94}$ particularly as the basic science achievements of the last decade are translated to the frontlines of care. The new NIH Roadmap initiative, ${ }^{95}$ along with related changes in the organization of our research agenda, ${ }^{96}$ represents a nascent recognition that our research infrastructure must be broadened to include more emphasis on the effectiveness of medical care and the translation of innovation from the bench not only to the bedside but also to the community. Increasingly, translational research will include a component of bidirectionality, recognizing the important role that communities and other new research partners can play in informing both the questions and methods of medical research. ${ }^{97}$

Achieving a goal of evidence-based practice will require practice-based evidence. Departments of family medicine are well positioned to link traditional research with the living laboratory required for this new kind of science. The case study by Schwenk and Green $^{98}$ from the University of Michigan describes the development of the research infrastructure necessary to work in the community in the context of a successful submission for an NIH Roadmap proposal. The commentary by Roper and Newton ${ }^{99}$ puts the experience in Michigan in national context, from the perspective of Dr Roper's leadership roles at the Health Care Financing Administration, the Centers for Disease Control and Prevention, and a commercial health insurer, and in public health, and his current role as dean and chief executive officer of the University of North Carolina Health Care System.

\section{AHCs as a Public Good}

Almost 40 years ago, Hardin ${ }^{100}$ described the tragedy of the commons:

"Picture a pasture open to all. It is to be expected that each herdsman will try to keep as many cattle as possible on the commons. Such an arrangement may work reasonably satisfactorily for centuries because tribal wars, poaching and disease keep the numbers of both man and beast well below the carrying capacity of the land. 
"Finally, however, comes the day of reckoning ... as a rational being, each herdsman seeks to maximize his personal gain. Explicitly or implicitly, he asks, 'what is the utility of me adding one more animal to my herd?' ... The rational herdsman concludes that the only sensible course for him to pursue is to add another animal to his herd. And another; and another. But this is the conclusion reached by each and every rational herdsman sharing a commons. Therein is the tragedy. Each man is locked into a system that compels him to increase his herd without limit - in a world that is limited."

AHCs represent a kind of commons - a public trust for the future of medicine and society. Public investment through the states, Medicare, Medicaid, NIH, and other branches of government has played a major role in the development of AHCs - and, over the last 2 generations, AHCs have played a major leadership role in the clinical and social success of American medicine. American medicine is graven in the image of the AHCs.

Now, however, medicine and society face new challenges. Our patients are changing, what medicine can do is expanding rapidly, and public accountability is high: the stakes are greater than ever before. The herdsman's incentive, however, is to continue to develop ever more elaborate technologies that may help individuals and individual AHCs, but may distract from or even worsen the health of the population.

To respond to this changed environment-and to continue to lead-AHCs must change substantially. The IOM report on the future of $\mathrm{AHCs}^{6}$ is an urgent call to attend to the commons, to respond to the changing needs of our society - and to move with urgency and impact. By pushing for change, by reinvigorating the relationship between AHCs and the communities they serve, and by emphasizing fundamental innovation across all missions, departments of family medicine can help lead the renewal of AHCs.

To read or post commentaries in response to this article, see it online at http://www.annfammed.org/cgi/content/full/4/suppl_1/s2

Key words: Academic health centers; finances; family medicine; family physicians; workforce; indigent care; community-based education; translational research; ambulatory care

Submitted April 10, 2006; accepted April 12, 2006.

\section{References}

1. Blumenthal D, Meyer GS. Academic health centers in a changing environment. Health Aff (Millwood). 1996;15:200-215.

2. Iglehart JK. Rapid changes for academic medical centers. 1. N Engl J Med. 1994;331:1391-1395.

3. Iglehart JK. Rapid changes for academic medical centers. 2. N Engl J Med. 1995;332:407-411.

4. Carey RM, Engelhard CL. Academic medicine meets managed care: a high-impact collision. Acad Med. 1996;71:839-845.
5. Iglehart JK. Support for academic medical centers-revisiting the 1997 Balanced Budget Act. N Engl J Med. 1999;341:299-304.

6. Institute of Medicine. Academic Health Centers: Leading Change in the 21st Century. Washington, DC: National Academies Press; 2003.

7. Task Force on Academic Health Centers. Envisioning the Future of Academic Health Centers. New York, NY: The Commonwealth Fund; 2004.

8. Aaron HJ. The Future of Academic Medical Centers. Washington, DC: Brookings Institution Press; 2001.

9. ICRAM (the International Campaign to Revitalise Academic Medi(ine): agenda setting. International Working Party to Promote and Revitalise Academic Medicine. BMJ. 2004;329:787-789.

10. Martin JC, Avant RF, Bowman MA, et al. The Future of Family Medicine: a collaborative project of the family medicine community. Ann Fam Med. 2004;2(Suppl 1):S3-S32.

11. Friedman $\mathrm{RH}$, Wahi-Gururaj S, Alpert J, et al. The views of U.S. medical school deans toward academic primary care. Acad Med. 2004;79:1095-1102.

12. Eberhardt M, Ingram D, Makuc D. Health, United States, 2001. Urban and Rural Health Chartbook. Hyattsville, Md: National Center for Health Statistics; 2001. Available at: http://www.cdc.gov/nchs/ data/hus/hus01cht.pdf. Accessed 23 October 2005.

13. Broermann RA, Kerner DJ, Walters HP, Hickman BM. Straight talk new approaches in healthcare. The outpatient market: protect important market share. Mod Healthc. 2003;33:29-32.

14. Boll A, Moore AJ, Brown JP, Kershaw JH, Flanigan BE. Ambulatory care growth: implications for academic organizations. J Ambul Care Manage. 1997;20:53-60.

15. Burns LR, Cacciamani J, Clement J, Aquino W. The fall of the house of AHERF: the Allegheny bankruptcy. Health Aff (Millwood). 2000;19:7-41.

16. Peterson SE, Rodin AE. GMENAC report on U.S. physician manpower policies: recommendations and reactions. Health Policy Educ. 1983;3:337-349.

17. Magill MK, Lloyd RL, Palmer D, Terry SA. Successful turnaround of a university-owned, community-based, multidisciplinary practice network. Ann Fam Med. 2006;4(Suppl 1):S12-S18.

18. Krugman RD. The Utah primary care experience. Ann Fam Med. 2006;4(Suppl 1):S19-S21.

19. Newton WP, DuBard CA, Wroth TH. New developments in primary care practice. N C Med J. 2005;66:194-204.

20. Asch SM, Kerr EA, Keesey J, et al. Who is at greatest risk for receiving poor-quality health care? N Engl J Med. 2006;354:1147-1156.

21. Institute of Medicine. The Chasm in Quality: Select Indicators from Recent Reports. Available at: http://www.iom.edu/subpage. asp?id=14980. Accessed 11 May 2005.

22. Lurie N, Buntin MB. Health disparities and the quality of ambulatory care. N Engl J Med. 2002;347:1709-1710.

23. Anderson G, Knickman JR. Changing the chronic care system to meet people's needs. Health Aff (Millwood). 2001;20:146-160.

24. Bodenheimer T, Wagner EH, Grumbach K. Improving primary care for patients with chronic illness. JAMA. 2002;288:1775-1779.

25. Bodenheimer $\mathrm{T}$, Wagner $\mathrm{EH}, \mathrm{Grumbach} \mathrm{K}$. Improving primary care for patients with chronic illness: the chronic care model, Part 2. JAMA. 2002;288:1909-1914.

26. Wagner EH, Austin BT, Davis $\mathrm{C}$, et al. Improving chronic illness care: translating evidence into action. Health Aff (Millwood). 2001;20:64-78.

27. Blumenthal D, Jennison Goonan K, Causion N. Promoting Quality Improvement at Academic Health Centers: Building on Pursuing Perfection. Boston, Mass: Institute for Health Policy; 2003.

28. Forrest CB, Whelan EM. Primary care safety-net delivery sites in the United States: a comparison of community health centers, hospital outpatient departments, and physicians' offices. JAMA 2000;284:2077-2083. 
29. Pew Health Professions Commission. Health Professions Education for the Future: Schools in Service to the Nation. Durham, NC: Pew Health Professions Commission; 1993.

30. PricewaterhouseCoopers' Health Research Institute. Acts of Charity: Charity Care Strategies for Hospitals in a Changing Landscape. Available at: http://pwchealth.com/cgi-local/hregister.cgi?link=reg/ charitycare.pdf. Accessed 23 October 2005.

31. Association of American Medical Colleges. Teaching Hospitals and Academic Physicians: Major Providers of Care for Medicaid Beneficiaries and Other Individuals Who Rely on Our Nation's Healthcare Safety Net. 2000-2001. Available at: http://www.aamc.org/advocacy/library/teachhosp/medicaid.pdf. Accessed 12 April 2006.

32. Gabow P, Eisert S, Wright R. Denver Health: a model for the integration of a public hospital and community health centers. Ann Intern Med. 2003:138:143-149.

33. Kaufman A, Derksen D, McKernan S, et al. Managed care for uninsured patients at an academic health center: a case study. Acad Med. 2000;75:323-330.

34. Baker GK, McKenzie AT, Harrison PB. Local physicians caring for their communities: an innovative model to meeting the needs of the uninsured. N C Med J. 2005;66:130-133.

35. Foreman S. Social responsibility and the academic medical center: building community-based systems for the nation's health. Acad Med. 1994;69:97-102.

36. Redington TJ, Lippincott J, Lindsay D, Wones R. How an academic health center and a community health center found common ground. Acad Med. 1995;70:21-26

37. Lowery K, Shi L, Weiner JP, Patow C. Money, mission, and medicine: an innovative managed care partnership between the community health centers of Maryland and Johns Hopkins University. J Ambul Care Manage. 1999;22:13-27.

38. Levine DM, Becker DM, Bone LR, et al. Community-academic health center partnerships for underserved minority populations: one solution to a national crisis. JAMA. 1994;272:309-311.

39. Cooksey JA, Kaur K, Matters MD, et al. Community health centers: unrecognized partners in health professions education. J Health Care Poor Underserved. 1999;10:349-361.

40. Kaufman A, Derksen D, Alfero C, et al. The Health Commons and care of New Mexico's uninsured. Ann Fam Med. 2006;4(Suppl 1): S22-S27.

41. Roth PB. Managing the uninsured with a community network. Ann Fam Med. 2006;4(Suppl 1):S28-S31.

42. White $\mathrm{KL}$, Williams TF, Greenberg BG. The ecology of medical care N Engl J Med. 1961;265:885-892.

43. Green LA, Fryer GE Jr, Yawn BP, Lanier D, Dovey SM. The ecology of medical care revisited. N Engl J Med. 2001;344:2021-2025.

44. Bloom SW. Structure and ideology in medical education: an analysis of resistance to change. J Health Soc Behav. 1988;29:294-306.

45. Christakis NA. The similarity and frequency of proposals to reform US medical education: constant concerns. JAMA. 1995;274:706-711.

46. Kassirer JP. Redesigning graduate medical education-location and content. N Engl J Med. 1996;335:507-509.

47. Goroll AH, Morrison G, Bass EB, et al. Reforming the core clerkship in internal medicine: the SGIM/CDIM Project. Society of General Internal Medicine/Clerkship Directors in Internal Medicine. Ann Intern Med. 2001;134:30-37.

48. Ewan C. Curriculum reform: has it missed its mark? Med Educ $1985 ; 19: 266-275$

49. Association of American Medical Colleges. The AAMC Project on the Clinical Education of Medical Students. Available at: http:// www.aamc.org/meded/clinicalskills/clinicalskillsnutter.pdf. Accessed 23 October 2005.

50. LeRoy LB. Meeting the challenge: a health workforce prepared for the future. Inquiry. 1994;31:334-337.
51. Schneider EC, Eisenberg JM. Strategies and methods for aligning current and best medical practices: the role of information technologies. West J Med. 1998;168:311-318.

52. Bulger RJ. Generalism and the need for health professional educational reform. Acad Med. 1995;70(1 Suppl):S31-S34.

53. Institute of Medicine. Health Professions Education: A Bridge to Quality. Washington, DC: National Academy Press; 2003.

54. Henderson T. Graduate Medical Education and Public Policy: A Primer. Washington, DC: US Health Resources and Services Administration; 2000. Available at: ftp://ftp.hrsa.gov/bhpr/nationalcenter/ GMEprimer.pdf. Accessed 8 August 2006.

55. Young JQ, Coffman JM. Overview of graduate medical education: funding streams, policy problems, and options for reform. West J Med. 1998;168:428-436.

56. Matherlee KR. The outlook for clinical research: impacts of federal funding restraint and private sector reconfiguration. Acad Med. 1995;70:1065-1072.

57. Cantor JC, Baker LC, Hughes RG. Preparedness for practice: young physicians' views of their professional education. JAMA. 1993;270:1035-1040

58. HarrisInteractive. Harris Poll \#69. Available at: http://www.harrisinteractive.com/harris_poll/index.asp?PID = 599. Accessed 8 September 2005.

59. Association of American Medical Colleges. FACTS-Applicants, Matriculants and Graduates. Available at: http://www.aamc.org/ data/facts/2005/2005s/r.htm. Accessed 28 March 2006.

60. Remen RN. Recapturing the soul of medicine: physicians need to reclaim meaning in their working lives. West J Med. 2001;174:4-5.

61. Finding Meaning in Medicine. Available at: http://www.meaninginmedicine.org/home.html. Accessed 28 March 2005.

62. Smith JK, Weaver DB. Capturing medical students' idealism. Ann Fam Med. 2006;4(Suppl 1):S32-S37.

63. Eckhert NL. Getting the most out of medical students' global health experiences. Ann Fam Med. 2006;4(Suppl 1):S38-S39

64. Phillips RL Jr, Dodoo M, Jaen CR, Green LA. COGME's 16th report to Congress: too many physicians could be worse than wasted. Ann Fam Med. 2005;3:268-270.

65. Cooper RA, Getzen TE, McKee HJ, Laud P. Economic and demographic trends signal an impending physician shortage. Health Aff (Millwood). 2002;21:140-154

66. Cooper RA. There's a shortage of specialists: is anyone listening? Acad Med. 2002;77:761-766.

67. Green LA, Dodoo MS, Ruddy G, et al. The Physician Workforce of the United States: A Family Medicine Perspective. Washington, DC: Rober Graham Center; 2004. Available at: http://www.graham-center.org/ PreBuilt/physician_workforce.pdf. Accessed 23 October 2005.

68. Starfield B. Primary care and health: a cross-national comparison. JAMA. 1991;266:2268-2271.

69. Starfield B, Shi L, Macinko J. Contribution of primary care to health systems and health. Milbank Q. 2005;83:457-502.

70. Baicker K, Chandra A. Medicare spending, the physician workforce, and beneficiaries' quality of care. Health Aff (Millwood). 2004;Suppl Web Exclusives:W4-184-W4-197.

71. Starfield B. Is primary care essential? Lancet. 1994;344:1129-1133.

72. Grumbach K. The ramifications of specialty-dominated medicine. Health Aff (Millwood). 2002;21:155-157.

73. Fisher ES, Wennberg DE, Stukel TA, et al. The implications of regional variations in Medicare spending. Part 1: the content, quality, and accessibility of care. Ann Intern Med. 2003;138:273-287.

74. Fisher ES, Wennberg DE, Stukel TA, et al. The implications of regional variations in Medicare spending. Part 2: health outcomes and satisfaction with care. Ann Intern Med. 2003;138:288-298. 
75. Rosenblatt RA, Andrilla CH, Curtin T, Hart LG. Shortages of medical personnel at community health centers: implications for planned expansion. JAMA. 2006;295:1042-1049.

76. Garibaldi RA, Popkave C, Bylsma W. Career plans for trainees in internal medicine residency programs. Acad Med. 2005;80:507-512.

77. Berg AO, Norris TE. A workforce analysis informing medical school expansion, admissions, support for primary care, curriculum, and research. Ann Fam Med. 2006;4(Suppl 1):S40-S44.

78. Boelen C. Adapting health care institutions and medical schools to societies' needs. Acad Med. 1999;74(8 Suppl):S11-S20.

79. Health Canada. Social Accountability: A Vision for Canadian Medical Schools. Available at: http://www.bcahc.ca/pdf/Social\%20Accou ntability\%20-\%20A\%20Vision\%20for\%20Canadian\%20Medical\%2 OSchools.pdf. Accessed 23 October 2005.

80. Rourke J. Social accountability in theory and practice. Ann Fam Med. 2006;4(Suppl 1):S45-S48.

81. Cappon P, Watson D. Improving the social responsiveness of medical schools: lessons from the Canadian experience. Acad Med. 1999;74(Suppl 8):S81-S90.

82. Brook RH, Berg MH, Schechter PA. Effectiveness of nonemergency care via an emergency room: a study of 116 patients with gastrointestinal symptoms. Ann Intern Med. 1973;78:333-339.

83. Institute of Medicine. Crossing the Quality Chasm: A New Health System for the 21st Century. Washington, DC: National Academy Press; 2001.

84. Clark CM, Fradkin JE, Hiss RG, et al. Promoting early diagnosis and treatment of type 2 diabetes: the National Diabetes Education Program. JAMA. 2000;284:363-365.

85. Institute of Medicine. Priority Areas for National Action: Transforming Health Care Quality. Washington, DC: National Academy Press; 2003.

86. McBride P, Schrott HG, Plane MB, Underbakke G, Brown RL. Primary care practice adherence to National Cholesterol Education Program guidelines for patients with coronary heart disease. Arch Intern Med. 1998;158:1238-1244.

87. Ni H, Nauman DJ, Hershberger RE. Managed care and outcomes of hospitalization among elderly patients with congestive heart failure. Arch Intern Med. 1998;158:1231-1236.
88. Samsa GP, Matchar DB, Goldstein LB, et al. Quality of anticoagulation management among patients with atrial fibrillation: results of a review of medical records from 2 communities. Arch Intern Med. 2000;160:967-973.

89. Legorreta AP, Liu X, Zaher CA, Jatulis DE. Variation in managing asthma: experience at the medical group level in California. Am J Manag Care. 2000;6:445-453.

90. Young AS, Klap R, Sherbourne CD, Wells KB. The quality of care for depressive and anxiety disorders in the United States. Arch Gen Psychiatry. 2001;58:55-61.

91. Perez-Stable EJ, Fuentes-Afflick E. Role of clinicians in cigarette smoking prevention. West J Med. 1998;169:23-29.

92. US Department of Health and Human Services. 2004 National Healthcare Disparities Report. Rockville, Md: US Department of Health and Human Services, Agency for Healthcare Research and Quality; 2004. AHRQ Publication No. 05-0014.

93. Pober JS, Neuhauser CS, Pober JM. Obstacles facing translational research in academic medical centers. FASEB J. 2001;15:2303-2313.

94. Frist WH. Federal funding for biomedical research: commitment and benefits. JAMA. 2002;287:1722-1724.

95. Division of Strategic Coordination, Office of Portfolio Analysis and Strategic Initiatives, National Institutes of Health. NIH Roadmap for Medical Research. Available at: http://nihroadmap.nih.gov/. Accessed 28 October 2005.

96. US Department of Health and Human Services. Institutional Clinical and Translational Science Award. 2006. Available at: http://grants. nih.gov/grants/guide/rfa-files/RFA-RM-06-002.html. Accessed 28 March 2006.

97. Thomas P, Griffiths F, Kai J, O'Dwyer A. Networks for research in primary health care. BMJ. 2001;322:588-590.

98. Schwenk TL, Green LA. The Michigan Clinical Research Collaboratory: following the NIH Roadmap to the community. Ann Fam Med. 2006;4(Suppl 1):S49-S54.

99. Roper WL, Newton WP. The role of academic health centers in improving health. Ann Fam Med. 2006;4(Suppl 1):S55-S57.

100. Hardin G. The tragedy of the commons. Science. 1968;162:1243 1248. 